\title{
ФИЗИКА
}

Том 177, № 3

декабрь, 2013

(C) 2013 г.

Ю. А. Григорьев*, В. А. Худобахшов*,

А. В. Цыганов*

\section{РАЗДЕЛЕНИЕ ПЕРЕМЕННЫХ \\ ДЛЯ НЕКОТОРЫХ СИСТЕМ С ИНТЕГРАЛОМ ДВИЖЕНИЯ ЧЕТВЕРТОЙ СТЕПЕНИ}

Построены переменные разделения для интегрируемых деформаций Яхьи в случае волчка Ковалевской и системы Чаплыгина на сфере. В общем случае соответствующие квадратуры представляют собой отображение Абеля-Якоби на двумерном подмногообразии якобиана алгебраической кривой рода три, которая не является гиперэллиптической.

Ключевые слова: бигамильтонова геометрия, разделение переменных, волчок Ковалевской.

DOI: $10.4231 / \operatorname{tmf} 8556$

\section{1. ВВЕДЕНИЕ}

В работах Яхьи найдено несколько интегрируемых деформаций волчка Ковалевской и системы Чаплыгина на сфере, т. е. при нулевом значении интеграла площадей (см. работы [1], [2] и более ранние, перечисленные в них). В настоящей работе мы строим переменные разделения для двух таких деформаций, следуя методу, предложенному в статьях [3], [4].

Чтобы описать фазовое пространство, рассмотрим алгебру Ли $e^{*}(3)$ группы Ли $E(3)$ движений трехмерного евклидова пространства. Физические координаты для динамической системы задаются с помощью вектора Пуассона $x=\left(x_{1}, x_{2}, x_{3}\right)$ и вектора углового момента $J=\left(J_{1}, J_{2}, J_{3}\right)$. Скобка Ли-Пуассона в этом случае задается следующими соотношениями:

$$
\left\{J_{i}, J_{j}\right\}=\varepsilon_{i j k} J_{k}, \quad\left\{J_{i}, x_{j}\right\}=\varepsilon_{i j k} x_{k}, \quad\left\{x_{i}, x_{j}\right\}=0,
$$

где $\varepsilon_{i j k}$ - полностью антисимметричный тензор. Эта скобка Пуассона обладает функциями Казимира

$$
C_{1}=|x|^{2} \equiv \sum_{k=1}^{3} x_{k}^{2}, \quad C_{2}=(x, J) \equiv \sum_{k=1}^{3} x_{k} J_{k} .
$$

* Санкт-Петербургский государственный университет, Санкт-Петербург, Россия. E-mail: yury.grigoryev@gmail.com, vitaly.khudobakhshov@gmail.com, andrey.tsiganov@gmail.com 